\title{
ARTICLE \\ Measurement of void fraction in bubbly-slug flow with a constant electric current method
}

\author{
Shinichiro Uesawa ${ }^{\mathrm{a}^{* \dagger}}$, Akiko Kaneko ${ }^{\mathrm{a}}$ and Yutaka Abe ${ }^{\mathrm{a}}$ \\ ${ }^{a}$ Department of Engineering Mechanics and Energy, University of Tsukuba, 1-1-1 Tennodai, \\ Tsukuba-shi, Ibaraki, 305-8573, Japan
}

In several void fraction measurement methods, a constant electric current method which is one of conductance methods is focused in the present study. By using this method, void fraction can be measured with higher temporal resolution. However, it has been mainly applied to annular flow in previous studies. In the present study, Maxwell's estimation, Bruggemann's estimation, low void fraction approximation and new estimations which consider the bubble shape are applied in order to measure more accurately void fraction of dispersed bubbly flow and slug flow. To understand the effect of bubble shapes and flow patterns, void fraction was measured by the constant electric current method for a rising single spherical bubble and a rising single slug bubble without a forced convection. In addition, void fraction was also measured in bubbly flow and bubbly-slug flow with a forced convection. Then, effects of flow patterns on the proposed estimations of void fraction and the accuracy of their estimations were discussed with the measurement results. From the result, the new estimations which consider a bubble shape are more accurate than the previous estimation in a slug bubble and bubbly-slug flow.

\section{Keywords; Gas-liquid two-phase flow; Bubbly flow; Bubbly-slug flow; Void fraction; Measurement; Constant electric current method}

\footnotetext{
*Corresponding author. Email: uesawa.shinichiro@jaea.go.jp

${ }^{\dagger}$ Present address: Japan Atomic Energy Agency, Tokai-mura Naka-gun, Ibaraki, 319-1195, Japan.
} 


\section{Introduction}

Volumetric void fraction is one of very important physical values and key parameters in two-phase flow for designs and performance evaluations of devices. Numerous measurement techniques of void fraction have been developed, and these have been applied to two-phase flow. A quick shut valves method can directly measure volumetric void fraction, but the method cannot measure the time variation of void fraction due to shut flow. Measurements with radiations as X-ray, $\gamma$-ray and neutron are highly advantageous to its non-intrusiveness and its ability to penetrate opaque wall materials. In addition, computed tomography systems can measure 2D and quasi-3D distributions of void fraction in vessels. However, these measurement systems need safety reasons and cost issues that come with radiation sources. In flow visualization and image processing with a nuclear magnetic resonance (NMR), the advantage is non-intrusive and non-invasive measurement of a phase distribution and a velocity field. However, the imaging technique cannot estimate flow structures with high void fraction, and then the instrumentation is expensive. In various void fraction measurement techniques, electric sensing techniques are inline measurement techniques with lower cost and simpler instrumentations. If conductivity or permittivity of two phase fluid is different from each other, the electric resistance and the capacitance change according to the void fraction. 2D and 3D distributions of void fraction are measured by CT techniques. However, the accuracy of the measurement is affected by temperature and electric compositions of the fluid.

For the measurement method of the resistance, a conductance void meter was developed to investigate the structures of bubbly two-phase flow[1]. The sensor was generally designed to be flush-mounted to the inner wall of the test section to avoid the flow disturbances. The sensor with a guard electrode which was electrically shielded was also developed in order not to affect the measurements of two-phase mixture conductance. A wire mesh method to bubble columns was applied and provided tomographic measurement images 
of void fraction with a time resolution of 1000 measurements per second and a wire gap of 3.5 $\mathrm{mm}[2]$. A technique with the electric resistance tomography measurement to bubble behaviors in bubble columns was also applied[3]. They measured 2D distributions of void fractions, Sauter mean bubble sizes and bubble rise velocities. The data collection rate was 9.5 frames per second with an excitation signal frequency of $38.4 \mathrm{kHz}$.

For utilization of permittivity, five capacitor configurations; parallel, strip-type plates, ring-type plates, unidirectional, and double-helix was manufactured and tested[4]. A capacitance wire mesh sensor with 5000 frame per second was developed and it obtained images of void fraction distributions, radial void fraction profiles and bubble size distributions[5]. Real-time flow structures in gas-liquid and gas-liquid-solid systems in a bubble column using electric capacitance tomography were measured[6]. Furthermore, recent advances and progress of electric capacitance volume tomography which provided the real-time and three-dimensional images of multi-phase flows with non-intrusiveness were described[7].

A constant electric current method is a measurement method of cross-sectional and volumetric average void fraction with high time resolution and simple principles[8]. The method has been applied to measure void fraction in annular flow and liquid film thickness[9-11]. However, the method cannot provide void fraction of three dimensional dispersed bubbly flow, because the void fractions are estimated with measured electric voltages on the assumption that a cross-section ratio of gas phase is constant in a flow direction. Meanwhile, Maxwell's estimation and Bruggemann's estimation were applied to measurements of void fractions in three dimensional dispersed bubbly flow by using a conductivity probe[12]. In the experimental results, Maxwell's estimation was in good agreement with the measured results. These estimations were applied in order to investigate the relationship between void fraction and volume-averaged impedance in water-air mixtures, too[13]. Gas volume fractions measured by the electric resistance tomography was also 
estimated by Maxwell's estimation[3]. In the constant electric current method, it was experimentally confirmed that Maxwell's estimation were more accurate estimation than the previous estimation for dispersed bubbly flow[14]. However, these studies did not discuss an effect of flow patterns and bubble shape on Maxwell's estimation and Bruggemann's estimation. The present study discussed the effect of flow pattern and bubble shape on these estimations of void fraction. In addition, new estimations taken account of flow patterns were proposed, and accuracy of the estimation was experimentally confirmed. In order to understand the effect of flow patterns and bubble shape, the constant electric current method was applied to a rising single spherical bubble and a rising single slug bubble without a forced convection. And then, void fraction was also measured by the constant electric current method in bubbly flow and bubbly-slug flow with a forced convection. Finally, the effects of flow patterns and bubble shape on void fraction estimations and the accuracy of the estimation were discussed in comparison with measurement results.

\section{Constant electric current method}

The constant electric current method is one of the conductance methods[8]. The method can provide cross-sectional and volumetric average void fraction. The principle and the system of the method are simple. For this reason, the time resolution is higher than other techniques although it cannot provide 2D and 3D distributions of void fraction such as wire mesh methods and tomography. In the constant electric current method, a constant electric current DC power supply applies to gas-liquid two-phase flow through a pair of electrodes which are mounted flush with a surface of a flow pass. These electrodes are called "applying electrodes”. A voltage is measured by a voltage drop method with another pair of electrodes which are set between the applied electrodes. These electrodes are called "measuring electrodes”. With this arrangement of electrodes, the voltage drop is picked-up through high impedance, then the electric current distribution is not disturbed with the presence of the pair 
of measuring electrodes. Besides, interaction among measuring electrodes is also negligible. Therefore, a number of measuring electrodes can be set in a short distance[8, 9, 14].

\section{Estimation methods of void fraction}

In the constant electric current method, a previous estimation method of void fraction is applied to a cross-sectional area of liquid phase between measuring electrodes[8]. A voltage ratio $v^{\prime}$ which is value of normalized voltage in gas-liquid two phase flow with voltage in liquid single flow is shown by void fraction $\alpha$.

$$
v^{\prime}=\frac{1}{1-\alpha}
$$

The void fraction $\alpha$ is estimated by electric voltage ratio $v$ ' as above. This method is applied to annular flow, because the cross-sectional area of liquid phase is assumed to be constant between measuring electrodes in the estimation method. However, the void fraction in bubbly flow cannot be accurately estimated from Equation (1), because bubbles are dispersed in three dimensions in bubbly flow.

Maxwell estimated a resistance of a mixture of two mediums which had different resistivity for each other in accordance with electromagnetism[14, 15]. In the present study, this estimation method is applied to the constant electric current method. Two mediums are assumed to be gas and liquid in this estimation. The void fraction is represented as,

$$
v^{\prime}=\frac{1+0.5 \alpha}{1-\alpha}
$$

The void fraction estimated by Maxwell's estimation Equation (2) is lower than the void fraction estimated by the previous method Equation (1), because $v^{\prime} \geq 1$. Unlike the previous method, the void fraction $\alpha$ in dispersed bubbly flow is expected to measure by Maxwell's estimation which calculates the resistance of gas-liquid two-phase flow in three dimensions. However, the theory is considered to be applicable when a gap between bubbles is longer than 
bubble diameter, because it is assumed that the spatial distribution and the electric interaction of each bubble are negligible.

Bruggemann also estimated a resistance of a mixture of two mediums which had different resistivity for each other in accordance with Maxwell's estimation[12]. In the present study, this estimation method is also applied to the constant electric current method. Two mediums are assumed to be gas and liquid in this estimation. The void fraction is represented as,

$$
v^{\prime}=(1-\alpha)^{-1.5}
$$

However, it implies the assumption of a large size-range of bubbles in surrounding medium.

When void fraction $\alpha<<1$, Equations (2) and (3) are approximated to the following Equation by Maclaurin expansion.

$$
v^{\prime}=1+1.5 \alpha
$$

In addition to the above estimations, in the present study, new estimations of void fraction are proposed in order to estimate accurately void fraction. These estimations of void fraction are estimated by calculating electric resistance taken account of bubble shapes and flow structures such as a spherical bubble, a slug bubble, bubbly flow and bubbly-slug flow as shown in Figure 1. When bubbles do not exist in a measurement section, the section is assumed to be filled with liquid. An electric resistance in the measurement section $R^{\prime}{ }_{L}$ is,

$$
R_{L}^{\prime}=\rho_{L}^{\prime} \frac{L}{S}=2 \int_{0}^{L / 2} \rho_{L}^{\prime} \frac{1}{S} d z
$$

where $\rho_{L}{ }_{L}$ is electric resistivity of liquid, $L$ is a length between measuring electrodes and $S$ is a cross-sectional area of a flow pipe.

\section{$<$ Figure 1>}

As shown in Figure 1(a), an electric resistance in the measurement section with a single spherical bubble $R^{\prime}{ }_{b}$ is, 


$$
R_{b}^{\prime}=2\left(\int_{0}^{r_{b}} \rho_{L}^{\prime} \frac{1}{S-S_{b}(z)} d z+\int_{r_{b}}^{L / 2} \rho_{L}^{\prime} \frac{1}{S} d z\right),
$$

where $S_{b}$ is a cross-sectional area of the single bubble in the flow direction. The bubble shape is assumed to be a sphere. The first term of the right side shows an electric resistance around the bubble. The second term of the right side shows an electric resistance without the bubble. If the flow direction is $z$-direction, the cross-sectional area $S_{b}$ for the bubble radius $r_{b}$ is,

$$
S_{b}=\pi x^{2}=\pi\left(r_{b}^{2}-z^{2}\right) \text {. }
$$

Equation (7) is substituted for Equation (6). Then, Equation (6) is integrated,

$$
R_{b}^{\prime}=2 \rho_{L}^{\prime} \frac{\tan ^{-1}\left(\frac{\sqrt{\pi} r_{b}}{\sqrt{S-\pi r_{b}^{2}}}\right)}{\sqrt{\pi} \sqrt{S-\pi r_{b}^{2}}}+\rho_{L}^{\prime} \frac{L}{S}-\rho_{L}^{\prime} \frac{2 r_{b}}{S} .
$$

Equation (8) shows the electric resistance in the measurement section when the single spherical bubble with the radius $r_{b}$ exists in the section. Calculating an electric voltage $V^{\prime} b$ by multiplying both sides by a constant electric current $I^{\prime}$,

$$
V_{b}^{\prime}=I^{\prime} R_{b}^{\prime}=2 I^{\prime} \rho_{L}^{\prime} \frac{\tan ^{-1}\left(\frac{\sqrt{\pi} r_{b}}{\sqrt{S-\pi r_{b}^{2}}}\right)}{\sqrt{\pi} \sqrt{S-\pi r_{b}^{2}}}+I^{\prime} \rho_{L}^{\prime} \frac{L}{S}-I^{\prime} \rho_{L}^{\prime} \frac{2 r_{b}}{S},
$$

is shown. By Equation (5), electric voltage of liquid single phase $V^{\prime}{ }_{L}$ is,

$$
V_{L}^{\prime}=I^{\prime} R_{L}^{\prime}=I^{\prime} \rho_{L}^{\prime} \frac{L}{S}
$$

Normalized Equation (9) by the electric voltage $V_{L}^{\text {' }}$, electric voltage ratio with a spherical bubble $v^{\prime} b$ is,

$$
v_{b}^{\prime} \equiv \frac{V_{b}^{\prime}}{V_{L}^{\prime}}=2 \frac{S}{L} \frac{\tan ^{-1}\left(\frac{\sqrt{\pi} r_{b}}{\sqrt{S-\pi r_{b}^{2}}}\right)}{\sqrt{\pi} \sqrt{S-\pi r_{b}^{2}}}+1-\frac{2 r_{b}}{L} .
$$

For a single spherical bubble, the increase of void fraction means increase of bubble radius. 
Volumetric void fraction $\alpha$ is,

$$
\alpha \equiv \frac{V_{G}}{V}=\frac{\frac{4}{3} \pi r_{b}^{3}}{L S} .
$$

Solving for the bubble radius $r_{b}$ gives,

$$
r_{b}=\left(\frac{3 L S \alpha}{4 \pi}\right)^{1 / 3}
$$

Substituting Equation (13) for Equation (11), the voltage ratio $v^{\prime}{ }_{b}$ is shown as the function of void fraction $\alpha$.

As shown in Figure 1(b), an electric resistance in the measurement section with a single slug bubble $R{ }^{\prime}$ is,

$$
\begin{aligned}
R_{s}^{\prime} & =\int_{r_{s}}^{L / 2} \rho_{L}^{\prime} \frac{1}{S} d z+\int_{0}^{r_{s}} \rho_{L}^{\prime} \frac{1}{S-S_{s 1}(z)} d z \\
& +\int_{-l}^{0} \rho_{L}^{\prime} \frac{1}{S-S_{s 2}} d z+\int_{-L / 2}^{-l} \rho_{L}^{\prime} \frac{1}{S} d z
\end{aligned}
$$

The first term and the forth term in the right side show resistances at the z-direction without the slug bubble. The second term shows a resistance with a bullet-shaped part of the slug bubble. The third term shows a resistance of a columnar part of the slug bubble. Here, the cross-sectional area in the z-direction of the bullet-shaped part $S_{s 1}^{\prime}$ and the columnar part of the slug bubble $S_{s 2}^{\prime}$ are,

$$
\begin{aligned}
& S_{s 1}^{\prime}=\pi x^{2}=\pi\left(r_{s}{ }^{2}-z^{2}\right), \\
& S_{s 2}^{\prime}=\pi r_{s}^{2} .
\end{aligned}
$$

The Equation (14) is assumed to hold when the radius of the bullet-shaped part of the slug bubble is equal to the radius in the cross-section direction of the columnar part. Using Equations (14), (15) and (16), the electric resistance in the measurement section with a slug bubble $R{ }_{S}$ is, 


$$
R_{s}^{\prime}=\rho_{L}^{\prime} \frac{L}{S}-\rho_{L}^{\prime} \frac{r_{s}}{S}+\rho_{L}^{\prime} \frac{\tan ^{-1}\left(\frac{\sqrt{\pi} r_{s}}{\sqrt{S-\pi r_{s}^{2}}}\right)}{\sqrt{\pi} \sqrt{S-\pi r_{s}^{2}}}-\rho_{L}^{\prime} \frac{l}{S}+\rho_{L}^{\prime} \frac{l}{\left(S-S_{s}\right)} .
$$

A voltage ratio in the measurement section $v^{\prime}{ }_{s}$ is,

$$
v_{s}^{\prime}=\frac{V_{s}^{\prime}}{V_{L}^{\prime}}=1-\frac{r_{s}}{L}+\frac{S}{L} \frac{\tan ^{-1}\left(\frac{\sqrt{\pi} r_{s}}{\sqrt{S-\pi r_{s}^{2}}}\right)}{\sqrt{\pi} \sqrt{S-\pi r_{s}^{2}}}+\frac{l}{L} \frac{\pi r_{s}^{2}}{S-\pi r_{s}^{2}} .
$$

A volumetric void fraction $\alpha$ in the section is estimated by the sum of the volume of the bullet-shaped part and the columnar part of the slug bubble.

$$
\alpha \equiv \frac{V_{G}}{V}=\frac{\frac{1}{2} \frac{4}{3} \pi r_{s}^{3}+\pi r_{s}^{2} l}{L S}
$$

If the increase of void fraction corresponded to the increase of the length of the slug columnar part, the length of the columnar part $l$ is,

$$
l=\frac{L S}{\pi r_{s}^{2}} \alpha-\frac{2}{3} r_{s}
$$

This equation is substituted for Equation (18). The electric voltage ratio in the section $v$ 's is,

$$
v_{s}^{\prime}=1-\frac{r_{s}}{L}+\frac{S}{L} \frac{\tan ^{-1}\left(\frac{\sqrt{\pi} r_{s}}{\sqrt{S-\pi r_{s}^{2}}}\right)}{\sqrt{\pi} \sqrt{S-\pi r_{s}^{2}}}+\frac{S}{S-\pi r_{s}^{2}} \alpha-\frac{2}{3} \frac{\pi r_{s}^{3}}{L\left(S-\pi r_{s}^{2}\right)} .
$$

In this equation, it is assumed that the slug length increases with an increase of the void fraction, and the radius of the slug bubble is constant.

As shown in Figure 1(c), an electric resistance in bubbly flow $R_{b f}^{\prime}$ is,

$$
R_{b f}^{\prime}=2 \int_{0}^{r_{b}} \rho_{L}^{\prime} \frac{1}{S-S_{b}(z)} d z \cdot \frac{L}{2 r_{b}}
$$

Bubbles are dealt with a single bubble which is the same volume as these bubbles in the cross-sectional direction (x-direction) as shown in Figure 1(c). Besides, the bubble shape is 
assumed to be a sphere with same radius $r_{b}$. As a single spherical bubble, the cross-sectional area $S_{b}$ of these dispersed bubble is estimated with the bubble radius $r_{b}$ as shown in Equation (7). Substituting Equation (7) for Equation (22) gives,

$$
R_{b f}^{\prime}=\rho_{L}^{\prime} \frac{\tan ^{-1}\left(\frac{\sqrt{\pi} r_{b}}{\sqrt{S-\pi r_{b}^{2}}}\right)}{\sqrt{\pi} \sqrt{S-\pi r_{b}^{2}}} \frac{L}{r_{b}} .
$$

An electric voltage ratio in the bubbly flow $v^{\prime} b f$ is,

$$
v_{b f}^{\prime}=\frac{S}{r_{b}} \frac{\tan ^{-1}\left(\frac{\sqrt{\pi} r_{b}}{\sqrt{S-\pi r_{b}^{2}}}\right)}{\sqrt{\pi} \sqrt{S-\pi r_{b}^{2}}} .
$$

A void fraction is estimated by multiplication of volume of a single bubble and the number of a bubble,

$$
\alpha \equiv \frac{V_{G}}{V}=\frac{\frac{4}{3} \pi r_{b}^{3} \frac{L}{2 r_{b}}}{L S}=\frac{2 \pi r_{b}^{2}}{3 S} .
$$

The bubble radius $r_{b}$ is,

$$
r_{b}=\sqrt{\frac{3 S \alpha}{2 \pi}} .
$$

Substituting Equation (26) for Equation (24),

$$
v_{b f}^{\prime}=\frac{2}{\sqrt{3 \alpha}} \frac{\tan ^{-1}\left(\frac{\sqrt{3 \alpha}}{\sqrt{2-3 \alpha}}\right)}{\sqrt{2-3 \alpha}},
$$

is shown. In the estimation of the above equation, it is assumed that bubbles did not overlap in the cross-sectional direction as shown in Figure 1(c). The voltage ratio $v^{\prime}{ }_{b f}$ depends on only the void fraction $\alpha$ by the assumption.

Applying above equations, bubbly-slug flow which consists of a slug bubble and dispersed bubbles is discussed as shown in Figure 1(d). Because the measuring electric resistance $R^{\prime}{ }_{b s f}$ is the sum of the resistance of the slug bubble $R^{\prime}{ }_{s 2}$ and dispersed bubbles $R^{\prime}{ }_{b f 2}$ 
in the model, Equation (17) for a single slug bubble and Equation (23) for bubbly flow is referred. Each resistance is shown as the following Equations,

$$
\begin{gathered}
R_{b s f}^{\prime}=R_{s 2}^{\prime}+R_{b f 2}^{\prime}, \\
R_{s 2}^{\prime}=\rho_{L}^{\prime} \frac{L_{s}}{S}-\rho_{L}^{\prime} \frac{r_{s}}{S}+\rho_{L}^{\prime} \frac{\tan ^{-1}\left(\frac{\sqrt{\pi r_{s}}}{\sqrt{S-\pi r_{s}^{2}}}\right)}{\sqrt{\pi} \sqrt{S-\pi r_{s}^{2}}}-\rho_{L}^{\prime} \frac{l}{S}+\rho_{L}^{\prime} \frac{l}{\left(S-\pi r_{s}^{2}\right)}, \\
R_{b f 2}^{\prime}=\rho_{L}^{\prime} \frac{\tan ^{-1}\left(\frac{\sqrt{\pi} r_{b}}{\sqrt{S-\pi r_{b}^{2}}}\right)}{\sqrt{\pi} \sqrt{S-\pi r_{b}^{2}}} \frac{L-L_{s}}{r_{b}} .
\end{gathered}
$$

The slug length $L_{s}$ is,

$$
L_{s}=r_{s}+l \text {. }
$$

By Equations (29), (30) and (31), Equation (28) becomes,

$$
\begin{aligned}
R_{b s f}^{\prime}= & \rho_{L}^{\prime} \frac{L_{s}}{S}-\rho_{L}^{\prime} \frac{r_{s}}{S}+\rho_{L}^{\prime} \frac{\tan ^{-1}\left(\frac{\sqrt{\pi} r_{s}}{\sqrt{S-\pi r_{s}^{2}}}\right)}{\sqrt{\pi} \sqrt{S-\pi r_{s}^{2}}}-\rho_{L}^{\prime} \frac{l}{S} \\
& +\rho_{L}^{\prime} \frac{l}{\left(S-\pi r_{s}^{2}\right)}+\rho_{L}^{\prime} \frac{\tan ^{-1}\left(\frac{\sqrt{\pi} r_{b}}{\sqrt{S-\pi r_{b}^{2}}}\right)}{\sqrt{\pi} \sqrt{S-\pi r_{b}^{2}}} \frac{L-r_{s}-l}{r_{b}}
\end{aligned} .
$$

An electric voltage ratio with bubbly-slug flow $v$ ' $b s f$ is,

$$
\begin{aligned}
v_{b s f}^{\prime}= & \frac{S}{L} \frac{\tan ^{-1}\left(\frac{\sqrt{\pi} r_{s}}{\sqrt{S-\pi r_{s}^{2}}}\right)}{\sqrt{\pi} \sqrt{S-\pi r_{s}^{2}}}+\frac{S}{r_{b}} \frac{\tan ^{-1}\left(\frac{\sqrt{\pi} r_{b}}{\sqrt{S-\pi r_{b}^{2}}}\right)}{\sqrt{\pi} \sqrt{S-\pi r_{b}^{2}}}\left(1-\frac{r_{s}}{L}\right) \\
+ & \frac{l}{L}\left[\frac{S}{\left(S-\pi r_{s}^{2}\right)}-\frac{S}{r_{b}} \frac{\tan ^{-1}\left(\frac{\sqrt{\pi} r_{b}}{\sqrt{S-\pi r_{b}^{2}}}\right)}{\sqrt{\pi} \sqrt{S-\pi r_{b}^{2}}}\right]
\end{aligned} .
$$


Here, a void fraction $\alpha$ is,

$$
\begin{aligned}
\alpha & \equiv \frac{V_{G}}{V} \\
& =\frac{\frac{1}{2} \frac{4}{3} \pi r_{s}^{3}+\pi r_{s}^{2} l+\frac{4}{3} \pi r_{b}^{3} \frac{L-L_{s}}{2 r_{b}}}{L S}, \\
& =\frac{\frac{2}{3} \pi r_{s}^{3}+\pi r_{s}^{2} l+\frac{2}{3} \pi r_{b}^{2}\left(L-r_{s}-l\right)}{L S}
\end{aligned}
$$

The length of the slug columnar part $l$ is,

$$
l=\frac{L S \alpha-\frac{2}{3} \pi r_{s}^{3}-\frac{2}{3} \pi r_{b}^{2}\left(L-r_{s}\right)}{\pi r_{s}^{2}-\frac{2}{3} \pi r_{b}^{2}}
$$

Substituting Equation (35) into Equation (33), v' bsf is,

$$
\begin{aligned}
v_{b s f}^{\prime}= & \frac{S}{L} \frac{\tan ^{-1}\left(\frac{\sqrt{\pi} r_{s}}{\sqrt{S-\pi r_{s}^{2}}}\right)}{\sqrt{\pi} \sqrt{S-\pi r_{s}^{2}}}+\frac{S}{r_{b}} \frac{\tan ^{-1}\left(\frac{\sqrt{\pi} r_{b}}{\sqrt{S-\pi r_{b}^{2}}}\right)}{\sqrt{\pi} \sqrt{S-\pi r_{b}^{2}}}\left(1-\frac{r_{s}}{L}\right) \\
+ & \frac{L S \alpha-\frac{2}{3} \pi r_{s}^{3}-\frac{2}{3} \pi r_{b}^{2}\left(L-r_{s}\right)}{L\left(\pi r_{s}^{2}-\frac{2}{3} \pi r_{b}^{2}\right)}\left[\frac{S}{\left(S-\pi r_{s}^{2}\right)}-\frac{S}{r_{b}} \frac{\tan ^{-1}\left(\frac{\sqrt{\pi} r_{b}}{\sqrt{S-\pi r_{b}^{2}}}\right)}{\sqrt{\pi} \sqrt{S-\pi r_{b}^{2}}}\right]
\end{aligned}
$$

In the estimation of Equation (36), the radius of the slug bullet-shaped part and the columnar part $r_{s}$ are assumed to be constant. Besides, the radius of dispersed bubbles $r_{b}$ is also assumed to be constant. Therefore, the length of the slug columnar part $l$ is expected to correspond to the void fraction $\alpha$.

\section{Experimental apparatus and condition}

An experimental apparatus to measure void fraction of a single bubble is shown in Figure 2. The experiment apparatus consists of a gas injection section, electric void sensors, an observation section, a measurement section of a water level and a void fraction measurement apparatus with a shut valve. The section of the gas injection consists of an 
acrylic pipe with an inner diameter of $20 \mathrm{~mm}$ and a manual ball valve made of polyvinyl chloride. The wall of the acrylic pipe is held with a hole in a diameter of $2 \mathrm{~mm}$ to inject gas by a syringe. The needle of the syringe is inserted into the hole of the pipe, and gas is injected. Several bubbles with a diameter of 1-10 mm are generated when gas is injected directly from the syringe. To make a single large bubble, several bubbles are corrected by closing the ball valve which is downstream of the injection point with the syringe. A single bubble flows into the test section by opening the ball valve after these bubbles coalesced. The interval between the gas injection and the center of the measuring section is $596 \mathrm{~mm}$. The void fraction measurement systems consist of an electric measurement system and a quick shut valve system. The inner diameter of the measurement sections is $16 \mathrm{~mm}$. As working fluids, tap water filtered with $5 \mu \mathrm{m}$-mesh and air were applied. The air injection quantity was $0-20 \mathrm{ml}$ in this experiment with a single bubble.

$<$ Figure 2>

An experimental apparatus to measure void fraction in bubbly flow and bubbly-slug flow is shown in Figure 3. It consists of a tank, a pump, a liquid flow meter, a compressor, a gas flow meter and void fraction measurement systems. A gas injection with a needle is applied in this experiment. Gas is supplied from the needle with inner diameter of $0.7 \mathrm{~mm}$. The interval between the gas injection and the center of the measuring section is $596 \mathrm{~mm}$. The inner diameter of the measurement sections is $16 \mathrm{~mm}$. The void fraction measurement systems consist of an electric measurement system and a quick shut valve system. In the experimental condition, tap water filtered with $5 \mu \mathrm{m}$-mesh and air were applied as the experiment of a single bubble. Gas flow rates were controlled in each superficial velocity of liquid $1.66 \mathrm{~m} / \mathrm{s}, 2.07 \mathrm{~m} / \mathrm{s}$ and $2.49 \mathrm{~m} / \mathrm{s}$. Gas volume flow ratios from 0 to 0.50 were applied.

$<$ Figure 3 $>$

As shown in Figure 4, four ring-shaped electrodes are used in the electric measurement system. These electrodes are made of stainless steel with the length of $10 \mathrm{~mm}$. 
The shape is flange type. The inner diameter of the electrode is $16 \mathrm{~mm}$ as the diameter of the flow path. Two outer electrodes (applying electrodes) are connected to a constant current DC power supply (model 6911, Metronix) and two inner electrodes (measuring electrodes) are connected to a data logger (NR-500 and NR-HA08, KEYENCE). The void fraction is estimated with the measuring voltage between two measuring electrodes by the voltage drop method. The sampling frequency was $100 \mathrm{kHz}$ and the measuring time was $0.5 \mathrm{~s}$. The interval of two measuring electrodes is $100 \mathrm{~mm}$, and then the interval of the applying electrode and the measuring electrode is $70 \mathrm{~mm}$. The flow path between electrodes is made of an acrylic resin which is an insulator. In order to observe the flow pattern between the measuring electrodes, the test section is made of a clear acrylic resin and is covered with a water jacket to decrease an influence of refraction. The flow was observed with a high-speed video camera (Phantom V12.1, Vision Research) and a metal halide lamp (HVC-UL, Photron).

$<$ Figure 4>

Measured voltages were revised with conductivity and temperature of water. The revision with conductivity is,

$$
V_{0}^{\prime}=\frac{\sigma_{m}^{\prime}}{\sigma_{0}^{\prime}} V_{m}^{\prime}
$$

where $V_{m}^{\prime}$ is measured voltage, $\sigma_{m}^{\prime}$ is measured conductivity, $\sigma_{0}^{\prime}$ is a benchmark of conductivity and $V_{0}^{\prime}$ is revised voltage for conductivity. The revision with temperature is,

$$
V_{t_{0}}^{\prime}=\left\{1+0.02\left(t_{m}-t_{0}\right)\right\} V_{m}^{\prime},
$$

where $t_{m}$ is temperature of gas-liquid two-phase flow, $t_{0}$ is benchmark of temperature and $V_{t 0}^{\prime}$ is revised voltage by temperature. 0.02 is a temperature correction factor and it is equivalent to factor of the conductivity meter. In this experiment, the conductivity was $300-310 \mu \mathrm{S} / \mathrm{cm}$ and the temperature was room temperature.

The void fraction was measured with the quick shut valve method in order to compare with the void fraction measured with the constant electric current method. Air cylinders which 
are set on the flow pass as shown in Figures 2 and 3 are operated with a solenoid valve connected to the compressor. Slide valves are made of stainless steel with thick of $0.5 \mathrm{~mm}$. In the experiment of bubbly flow and bubbly-slug flow as shown in Figure 3, they are set on the upstream and the downstream, and then they close the flow path at the same time. The void fraction was measured with observations of a water level after separation of gas from liquid. The measurement error was $10 \%$. The void fraction were measured with 10 times for each experimental condition.

\section{Experimental results and discussion}

\subsection{Void fraction measurement of a single bubble}

For a single rising bubble without a forced convection, the bubble behavior was observed, and then electric voltage was measured by the constant electric current method with the experiment apparatus as shown in Figures 2 and 4. Figure 5 shows observation results of a bubble behavior and time variation of voltage for the injection quantity about $0.5 \mathrm{ml}$. The both results are the observation and the voltage measurement between measuring electrodes. The voltage measurement was synchronized with the observation of the bubble behavior in order to discuss the effect of the bubble behavior. In the observation result, black rectangles upside and downside of the observation result in each time are ring electrodes of upstream and downstream. The rising sphere is the bubble. The voltage ratio was obtained by normalizing with measured voltage before the bubble flow into the test section between $0.0 \mathrm{~s}$ and $0.1 \mathrm{~s}$. In the time variation of the voltage ratio, the amplitude of the voltage ratio became gradually large from $0.1 \mathrm{~s}$. The bubble flowed into the test section at the time. The gradual increase of the voltage ratio is due to be caused by difference of line of electric forces around a bubble between center of electrodes and near the electrodes. Then, the voltage ratio fluctuated until the bubble flowed out of the measuring section at $0.95 \mathrm{~s}$. In the interval, the measured voltage ratio did not correlate with the rising position of the bubble. Hence the 
vertical position of a bubble did not affect the measurement of the voltage ratio. However, the voltage ratio fluctuated in the time of $0.25-0.80 \mathrm{~s}$. The amplitude was small, but the amplitude range was $1.045-1.055$ [-]. Here, the fluctuation is considered not to be electric noise because the fluctuation was not measured before inflow of the bubble to the measuring region. The fluctuation is expected to be the phenomenon caused by the bubble. As shown in the observation result, the interface of the rising bubble deformed. The shape became an ellipse from a sphere, or a sphere from an ellipse. In comparison of the voltage fluctuation with the bubble behavior, it was confirmed that the voltage ratio was lower when the shape of the bubble was a sphere. On the other hand, the voltage ratio was higher when the shape was an ellipse. Therefore, the voltage ratio changes by variation of cross-section ratio between gas and liquid with the deformation. The voltage variation is $0.01[-]$, and then the variation means variation of void fraction of $0.01[-]$ at the maximum in estimations proposed in the present study. In addition, the voltage ratio of 1.004 [-] was measured after 0.95 sec although the bubble flowed out of the measuring section. This cause is considered to be affected by an electric capacity in the measuring section. The voltage ratio of $1.004[-]$ means void fraction of $0.004[-]$ at the maximum in estimations proposed in the present study.

$<$ Figure 5 $>$

To validate estimation methods of void fraction for a single bubble, the experiment as shown in Figures 2 and 4 was conducted for the amount of the injected gas. Observation results between measuring electrodes are shown in Figure 6. A spherical bubble was observed below the void fraction of 0.007 [-]. Above the void fraction of 0.133 [-], a slug bubble was observed in the measuring section. The columnar part of the slug bubble became longer with an increase of the void fraction. The slug diameters at the center of the slug in the flow direction $D_{\text {s }}$ were $13.5 \mathrm{~mm}$ in $\alpha=0.238,14.2 \mathrm{~mm}$ in $\alpha=0.458,14.8 \mathrm{~mm}$ in $\alpha=0.675$ and $14.8 \mathrm{~mm}$ in $\alpha=0.804$ as shown in Figure 6. Importantly, the slug diameter was constant above $\alpha=0.675$. This means that the increase of the void fraction was caused by the increase 
of the slug length in high void fraction.

$<$ Figure 6>

The correlation of the voltage ratio and the void fraction is shown in Figure 7. Symbols in Figure 7 show the time average values. Standard deviations are below $0.1[-]$. Here, void fractions between 0.0 and 0.11 were measured by the observation. The volume of the bubble was estimated by assuming that the bubble was a sphere. Void fractions between $0.13[-]$ and $0.91[-]$ were measured by the measurement of a water level with the shut method. From the results, it was confirmed that the voltage ratio correlate with the void fraction. The voltage ratio increased with an increase of the void fraction. In comparison of these experimental results with estimations - such as the previous method (Equation (1)), Maxwell's estimation (Equation (2)), Bruggemann's estimation (Equation (3)), low void fraction approximation (Equation (4)), new estimation for a spherical bubble (Equations (11) and (13)), and new estimation for a slug bubble (Equation (21)), experimental results were coincident with the new estimation for slug bubble (Equation (21)) with the slug radius $r_{s}=$ $7.2 \mathrm{~mm}$ obtained by least squares method. On the other hand, the previous estimation, Maxwell's estimation, Burggemann's estimation and low void fraction approximation underestimated voltage ratio below $\alpha=0.5$.

\section{$<$ Figure $7>$}

Figure 8 shows the correlation between the voltage ratio and the void fraction, and the comparisons with various estimations of the void fraction in low void fraction below $\alpha=0.05$ [-]. It was confirmed that the voltage ratio increased with an increase of the void fraction in low void fraction, too. Above the void fraction $\alpha=0.018$ [-], new estimation for a slug bubble with the slug radius $r_{s}=7.2 \mathrm{~mm}$ was coincident with experimental data. The reason is considered that the bubble shape become elliptical shape and the horizontal diameter approach the slug diameter of the estimation above $\alpha=0.018[-]$ as shown in Fig. 6. Other estimations underestimated the voltage ratio. Below the void fraction $\alpha=0.011$, the new 
estimation for a slug bubble also underestimated the voltage ratio because the bubble shape became a sphere from a slug shape with the decrease of the void fraction. This result was confirmed by the observation results in Figure 6. The interface between gas and liquid reached near the wall of the flow pass, and bubble shape was not sphere in the void fraction $\alpha=0.018$ [-]. Below the void fraction $\alpha=0.007$ [-], the gas-liquid interface of the bubble was separate from the wall, and the bubble shape was comparatively a sphere. In addition, experimental results was comparatively coincident with Maxwell's estimation and Burggemann's estimation below void fraction $\alpha=0.005$ [-]. However, the new estimation for a spherical bubble and the previous estimation underestimated voltage ratio. Therefore, the bubble shape is important for the void fraction measurement with the constant electric current method. Especially, the new estimation for a slug bubble can estimate more accurately the void fraction than the previous estimation, Maxwell's estimation Burggemann's estimation above the void fraction $\alpha=0.018[-]$.

\section{$<$ Figure 8 $>$}

Figure 9 shows the comparison between experimental results and the new void fraction estimation for a slug bubble diameter $D_{s}$. It was confirmed that experimental results was covered the new void fraction estimation for a slug bubble diameter $D_{s}=13.6 \mathrm{~mm}-14.6$ mm. These values were coincident with the observation result as shown in Figure 6. In addition, the estimations in large $D_{s}$ were coincident comparatively with experimental results in higher void fraction. In comparison of the observation results in the void fraction $\alpha=0.238$ [-] with 0.675 [-], the slug bubble diameter in the void fraction $\alpha=0.238$ [-] was shorter than the diameter in $\alpha=0.675$ [-]. This observation results agreed with the result of the voltage ratio as shown in Figure 9. Therefore, the slug bubble diameter is the important parameter for the void fraction measurement by the constant electric current method.

$<$ Figure 9> 


\subsection{Void fraction measurement of bubbly flow}

In this section, accuracy of each estimation method - such as the previous method (Equation (1)), Maxwell's estimation (Equation (2)), Bruggemann's estimation (Equation (3)), low void fraction approximation (Equation (4)), new estimation for bubbly flow (Equation (27)), and new estimation for a bubbly-slug flow (Equation (36)) for dispersed bubbly flow is experimentally discussed. Bubble behaviors in the bubbly flow for each void fraction are shown in Figure 10. These observation results were high speed video camera images between measuring electrodes with the superficial velocity of liquid $j_{L}=1.66 \mathrm{~m} / \mathrm{s}$. In the void fraction $\alpha=0.057$ [-], dispersed bubbly flow was observed. Above the void fraction $\alpha=0.146$ [-], bubbly-slug flow was observed. The bubble diameters in bubbly flow and bubbly-slug flow were estimated to be 2 - $3 \mathrm{~mm}$ by the observation results. The slug diameters at the center in the flow direction $D_{s}$ were $10.0 \mathrm{~mm}$ in $\alpha=0.183,11.5 \mathrm{~mm}$ in $\alpha=0.260$ and $12.0 \mathrm{~mm}$ in $\alpha=$ 0.312 as shown in Figure 10.

$<$ Figure 10>

Figure 11 shows the correlation between the voltage ratio and the void fraction in the bubbly flow and the bubbly-slug flow. Symbols are decided with time average values measured by the constant electric current method and average values of values measured by the quick shut method. Error bars of the voltage ratio are standard deviations of the time-average results. Error bars of the void fraction show the maximum values and the minimum value, which were measured by the quick shut method. With superficial velocities of liquid $j_{L}=1.66 \mathrm{~m} / \mathrm{s}, 2.07 \mathrm{~m} / \mathrm{s}$ and $2.49 \mathrm{~m} / \mathrm{s}$, the voltage ratio increased with an increase of the void fraction. The standard deviation of the voltage ratio became larger with an increase of the void fraction, because the slug bubble grew larger with an increase of void fraction and then the distribution of the void fraction in the flow direction was not homogeneous. In addition, the experimental result were compared with each estimation method in Figure 11. The new estimation for bubbly-slug flow with $r_{s}=5.9 \mathrm{~mm}$ and $r_{b}=0.5 \mathrm{~mm}$ was coincident 
with experimental results below the void fraction $\alpha=0.2$ [-]. On the other hand, the previous estimation, Maxwell's estimation and Burggemann's estimation underestimated the voltage ratio below the void fraction $\alpha=0.2$ [-]. Above the void fraction $\alpha=0.2$ [-], the value of the new estimation for bubbly-slug flow was near results estimated by Maxwell's estimation and Burggemann's estimation. These estimations were coincident with experimental results. Therefore, the new estimation for bubbly-slug flow was more accurate than other estimation methods below the void fraction $\alpha=0.30[-]$.

$<$ Figure 11>

Figure 12 shows the correlation between the voltage ratio and the void fraction below the void fraction $\alpha=0.10$ [-].The new estimation for bubbly-slug flow with $r_{s}=5.9 \mathrm{~mm}$ and $r_{b}=0.5 \mathrm{~mm}$ was coincident with experimental results in comparison with other estimations. The new estimation is applicable to bubbly flow as shown in Fig. 10 ( $\alpha=0.057[-])$. The reason is that the slug length becomes shorter and the bubbly flow region in the new estimation becomes larger with decrease of void fraction. However, in void fraction $\alpha=0.02$ [-], the result of the new estimation for bubbly-slug flow was not different from the results of low void fraction approximation, Burggemann's estimation and Maxwell's estimation. Moreover, these estimated results were coincident with experimental results. Therefore, the new estimation for bubbly-slug flow was most accurate estimation above the void fraction $\alpha$ $=0.02[-]$. Near the void fraction $\alpha=0.02[-]$, Maxwell's estimation, Burggemann's estimation, low void fraction approximation, the new estimation for bubbly-slug flow were more accurate than the previous estimation and the new estimation for bubbly flow. From these results, it is proposed that the void fraction measurement by the constant electric current method is applicable to bubbly flow and bubbly-slug flow.

$<$ Figure 12>

Figure 13 shows the comparison between the experimental result and the new void fraction estimation of bubbly-slug flow with the radius of spherical bubbles $r_{b}=0.5 \mathrm{~mm}$ for 
the parameter of a slug bubble diameter $D_{s}$. It was confirmed that experimental results were covered by the new void fraction estimation for the bubbly-slug flow with the slug bubble diameter of $D_{s}=11-12.6 \mathrm{~mm}$. In observation results as shown in Figure 10, slug bubble diameters were 10.0 - $12.0 \mathrm{~mm}$, and then they were coincident with $D_{s}$.

$<$ Figure 13>

Figure 14 shows the comparison between experimental results and the new void fraction estimation of bubbly-slug flow with the radius of a slug bubble $r_{s}=5.9 \mathrm{~mm}$ for the parameter of dispersed bubble diameter $D_{b}$. It was confirmed that experimental results were covered by the new void fraction estimation for dispersed bubble diameter of $D_{b}=0.2 \mathrm{~mm}-$ $2.0 \mathrm{~mm}$. However, increasing dispersed bubble diameter, the estimation was independent with dispersed bubble diameter as shown in results between $D_{b}=0.2 \mathrm{~mm}$ and $2.0 \mathrm{~mm}$. In the observation result as shown in Figure 10, bubble diameters were 2-3 mm. This result means that the new estimation for bubbly-slug flow does not depend on dispersed bubble diameter. Especially, the slug diameter is more effective than dispersed bubble diameter to the estimated void fraction in this experiment. As shown in Equation (34), this reason is that the new estimation for bubbly-slug flow is more sensitive to volume of a slug bubble (the first and second terms of the right side in Equation (34)) than volume of spherical bubbles (the third terms of the right side in Equation (34)) in this experiment as range of Ds $=11 \mathrm{~mm}-12.6 \mathrm{~mm}$ and $\mathrm{Db}=0.2 \mathrm{~mm}-2 \mathrm{~mm}$.

$<$ Figure 14>

Time series of bubble behavior and the void fraction in the superficial velocity of liquid $j_{L}=1.66 \mathrm{~m} / \mathrm{s}$ is shown in Figure 15. The horizontal axis is time and the vertical axis is the void fraction. The void fraction was estimated with the new estimation for bubbly-slug flow (equation (36)) with $r_{s}=5.9 \mathrm{~mm}$ and $r_{b}=0.5 \mathrm{~mm}$, because the estimation was considered to be applicable for bubbly-slug flow region from the results as shown in Fig. 11. Plots in this Figure show 0.329, 0.187, 0.072 and 0.006 [-] of time-average void fractions. The 
time-average void fractions of 0.329 [-] and 0.187 [-] in bubbly-slug flow fluctuated largely in comparison of fluctuations of time-average void fractions of $0.072[-]$ and 0.006 [-] in dispersed bubbly flow. Snapshots in Figure 15 are the observation results between measuring electrodes in the void fraction of 0.329 [-]. In comparison of the fluctuation of void fraction 0.329 [-] with the observation results, the void fraction was the minimum in the time-average void fraction 0.329 [-] when dispersed bubbles existed in the test section at $0.264 \mathrm{~s}$. Moreover, the rapid increase of void fraction to 0.6 [-] from $0.2[-]$ was confirmed in according to inflow of a large bubble between $0.264 \mathrm{~s}$ and $0.292 \mathrm{~s}$. From $0.292 \mathrm{~s}$ to $0.317 \mathrm{~s}$, a large bubble flowed out the section when the void fraction decreased rapidly to 0.2 [-] from 0.6 [-]. Therefore, the constant electric current method is possible to measure continuously the variation of the volumetric void fraction in bubbly-slug flow.

$<$ Figure 15 $>$

\section{Conclusion}

In the present study, the constant electric current method was applied to a single bubble and dispersed bubbly flow. Especially, the present study discussed the effect of flow pattern on estimation methods which estimate void fraction with voltage ratio. Moreover, new estimations considered flow patterns were proposed, and then the accuracy of the estimation was experimentally confirmed. In order to understand the effect of flow patterns, void fraction was measured by the constant electric current method for a single bubble and a single slug bubble without forced convection. The void fraction of bubbly flow and bubbly-slug flow were also measured by the constant electric current method. Then, the effects of flow patterns on void fraction estimations and the accuracy of the estimation were discussed with the measurement results.

In the experiment with a single bubble, the voltage ratio increased with an increase of the void fraction. The time series of the voltage ratio was stable for the bubble position in the 
flow direction. However, voltage ratio changed with the deformation of the bubble. In comparison of estimation methods with experimental results, the new estimation for a slug bubble is more effective in a slug bubble. The estimations in large $D_{s}$ are comparatively coincident with experimental results in higher void fraction.

In the experiment with bubbly flow and bubbly-slug flow, the voltage ratio increased with an increase of the void fraction as a single bubble. In comparison estimation methods with experimental results, the new estimation for bubbly-slug flow is more effective in bubbly-slug flow above the void fraction. Near the void fraction $\alpha=0.2[-]$, Maxwell's estimation, Burggemann's estimation, low void fraction approximation, the new estimation for bubbly-slug flow are more accurate than the previous estimation and the new estimation for bubbly flow. Therefore, it is proposed that the void fraction measurement by the constant electric current method is applicable to bubbly-slug flow. Moreover, in the new estimation for bubbly-slug flow, the slug diameter is more effective than dispersed bubble diameter to estimated void fractions in bubbly flow and bubbly-slug flow.

Time series of void fraction was compared with bubble behavior. From the experimental result, it was confirmed that temporal fluctuations of void fraction in the three dimensional dispersed bubbly flow is possible to be continuously measured.

Therefore, by applying the new estimation method for bubbly-slug flow which is proposed in this paper, the constant electric current method is possible to estimate void fraction of vertical upward bubbly-slug flow below liquid velocity $2.49 \mathrm{~m} / \mathrm{s}$ in a pipe with an inner diameter of $16 \mathrm{~mm}$, which has been measured in this experiment.

\section{Nomenclature}

I’ constant electric current [A]

L $\quad$ length between measuring electrodes [m]

$L_{s} \quad$ slug length [m] 


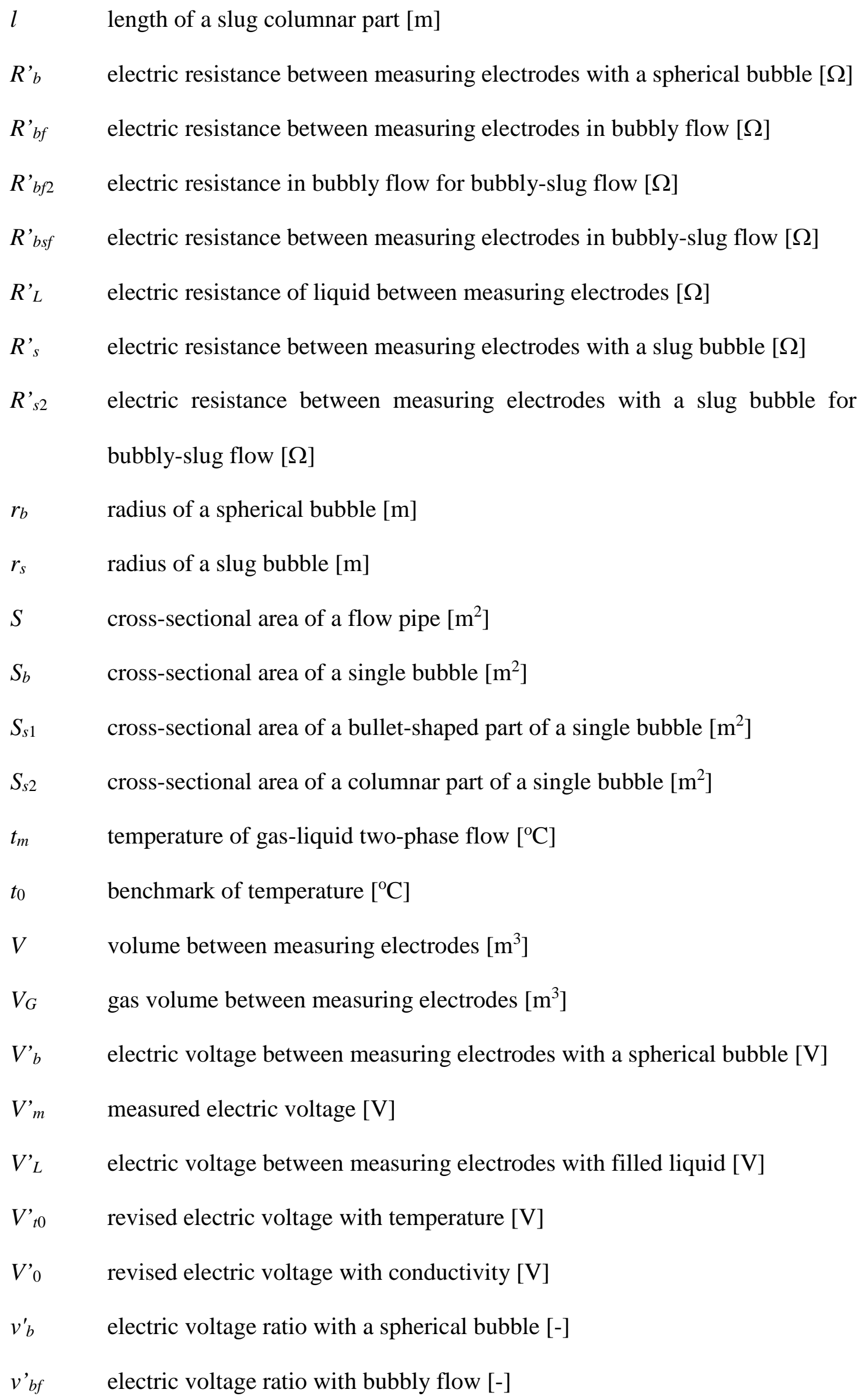




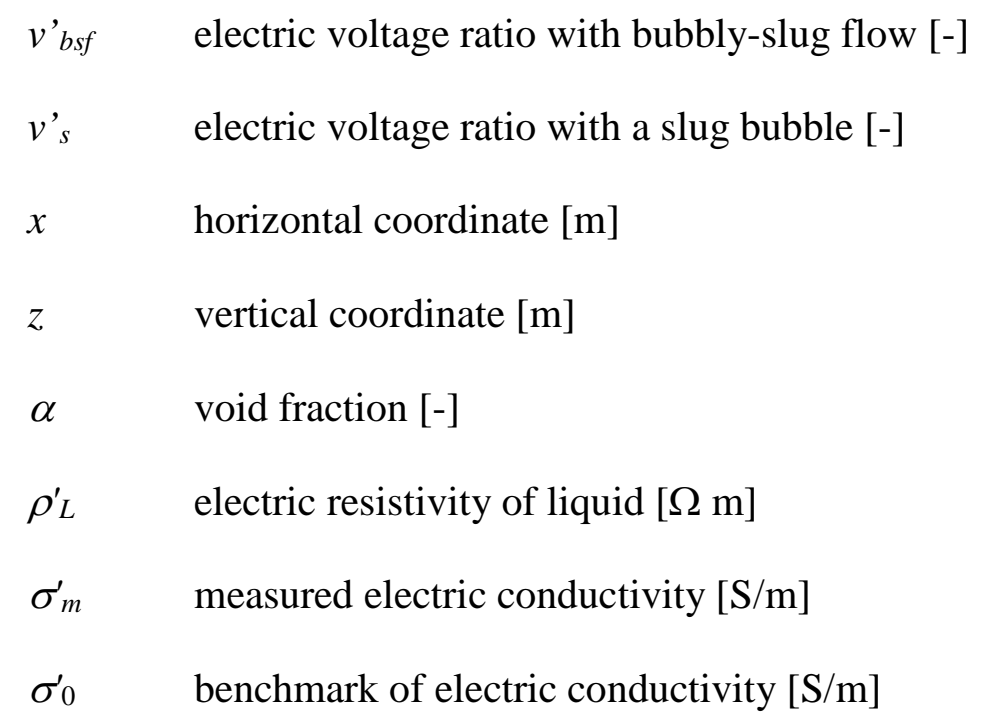

\section{References}

[1] Song CH, Chung MK, No HC. Measurements of void fraction by an improved multi-channel conductance void meter. Nucl. Eng. Des. 1998 Aug; 84:269-285.

[2] Kanai T, Furuya M, Arai T, Shirakawa K, Nishi Y. Three-dimensional phasic velocity determination methods with wire-mesh sensor. Int. J. Multiphase Flow. 2012 June; 46:75-86.

[3] Jin H, Wang M, Williams RA. Analysis of bubble behaviors in bubble columns using electric resistance tomography. Chem. Eng.J. 2007 June; 130:179-185.

[4] Kendoush AA, Sarkis ZA. Improving the Accuracy of the Capacitance Method for Void Fraction Measurement. Exp. Therm. Fluid Sci. 1995 Nov; 11:321-326.

[5] Silva MJ, Thiele S, Abdulkareemb L, Azzopardi BJ, Hampel U. High-resolution gas oil two-phase flow visualization with a capacitance wire-mesh sensor. Flow Meas. Inst. 2010 Sep; 21:191-197.

[6] Warsito W, Fan LS. Measurement of real-time flow structures in gas-liquid and gas-liquid-solid flow systems using electric capacitance tomography (ECT). Chem. Eng. Sci. 2001 Nov; 56:6455-6462.

[7] Wang F, Marashdeh Q, Fan LS, Warsito W. Electric Capacitance Volume Tomography: 
Design and Applications. Sens. 2010 Jan; 10:1890-1917.

[8] Fukano T. Measurement of time varying thickness of liquid film flowing with high speed gas flow by a constant electric current method (CECM). Nucl. Eng. Des. 1998 Aug; 184:363-377.

[9] Ide H, Kariyasaki A, Fukano T. Fundamental data on the gas-liquid two-phase flow in minichannels. Int. J. Therm. Sci. 2007 June; 46:519-530.

[10] Furukawa T, Matsuyama F, Sadatomi M. Effects of Reduced Surface Tension on Liquid Film Structure in Vertical Upward Gas-Liquid annular Flows. J. Power Energy Syst. 2010 Feb; 4:1-11.

[11] Deendarlianto, Ousaka A, Indarto, Kariyasaki A, Lucas D, Vierow K, Vallee C, Hogan K. The effects of surface tension on flooding in counter-current two-phase flow in an inclined tube. Exp. Therm. Fluid Sci. 2010 Oct; 34:813-826.

[12] Sigrist L, Dossenbach O, Ibl N. On the conductivity and void fraction of gas dispersions in electrolyte solutions. J. Appl. Electrochem. 1980 March; 10:223-228.

[13] Yang HC, Kim DK, Kim MH. Void fraction measurement using impedance method. Flow Meas. Inst. 2003 Aug-Oct; 14:151-160.

[14] Uesawa S, Kaneko A, Abe Y. Measument of Void fraction in Dispersed Bubbly Flow Containing Micro-bubbles with Constant Electric Current Method. Flow Meas. Inst. 2012 April; 24:50-62.

[15] Maxwell JC. A Treatise on Electricity \& Magnetism Vol. 1. NEW YORK: Dover Publications Inc.; 1954. 435-441. 


\section{Figure captions}

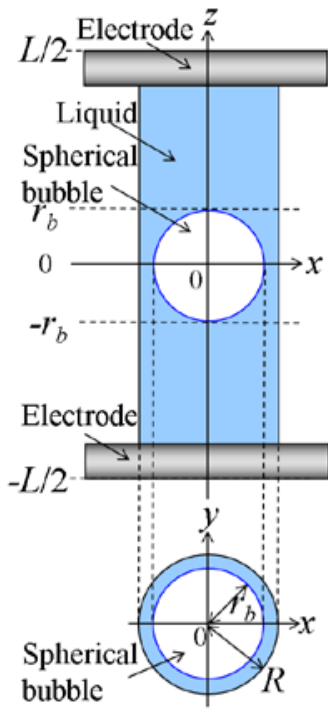

(a) Spherical bubble

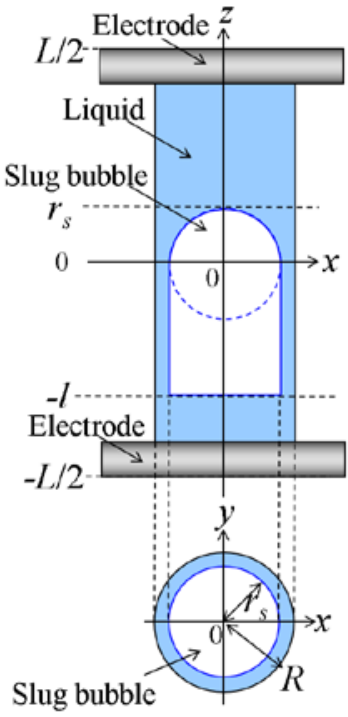

(b) Slug bubble

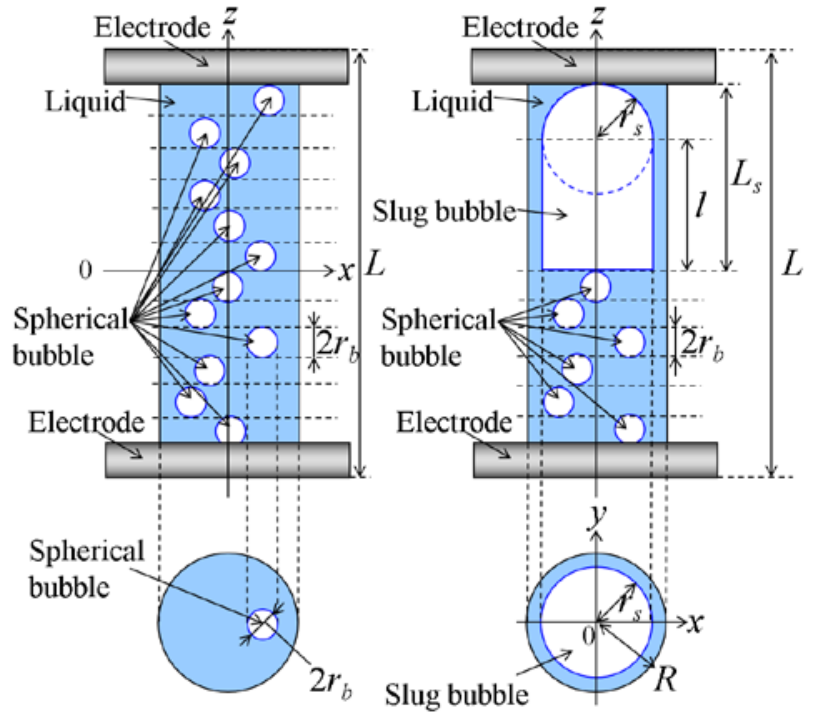

(c) Bubbly flow

(d) Bubbly-slug flow

Figure 1. A schematic of new estimation models of void fraction in each flow condition.

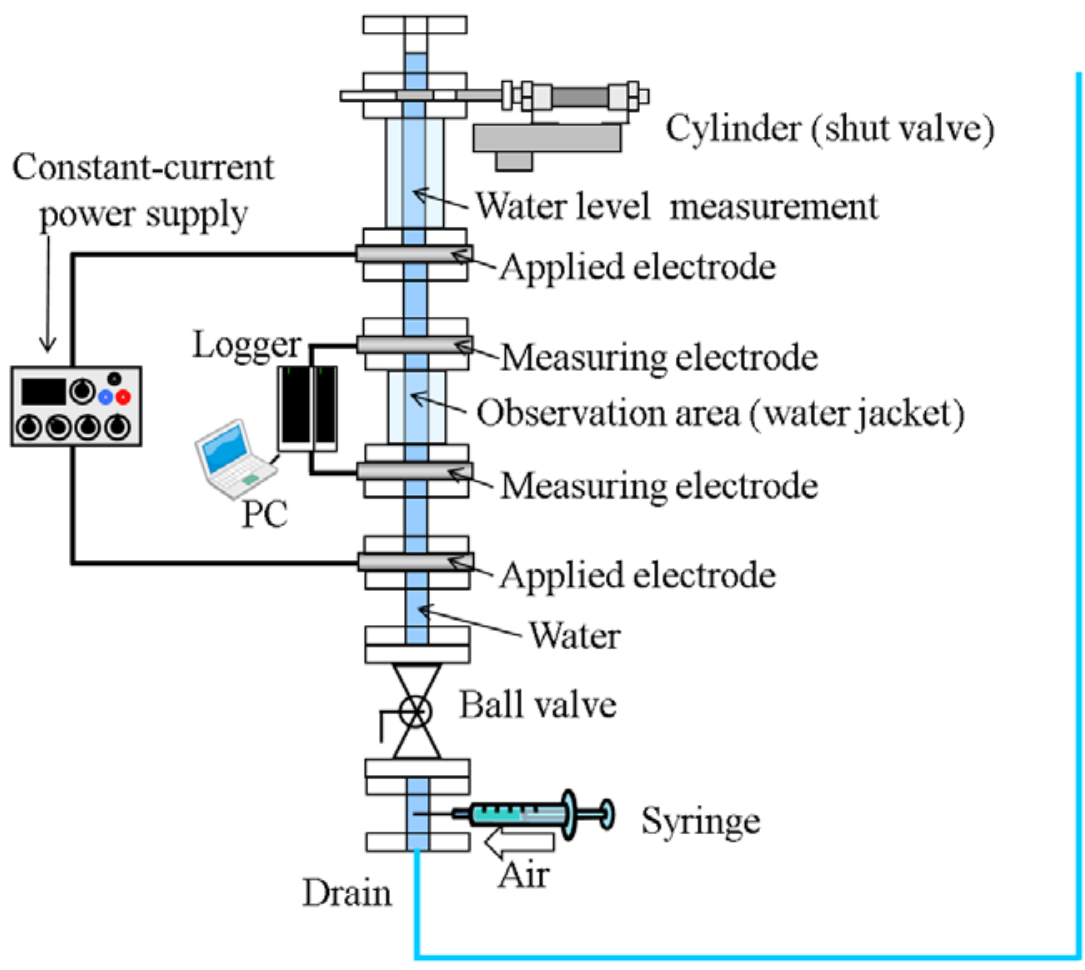

Figure 2. A schematic of the experimental setup to measure a single bubble without forced convection. 


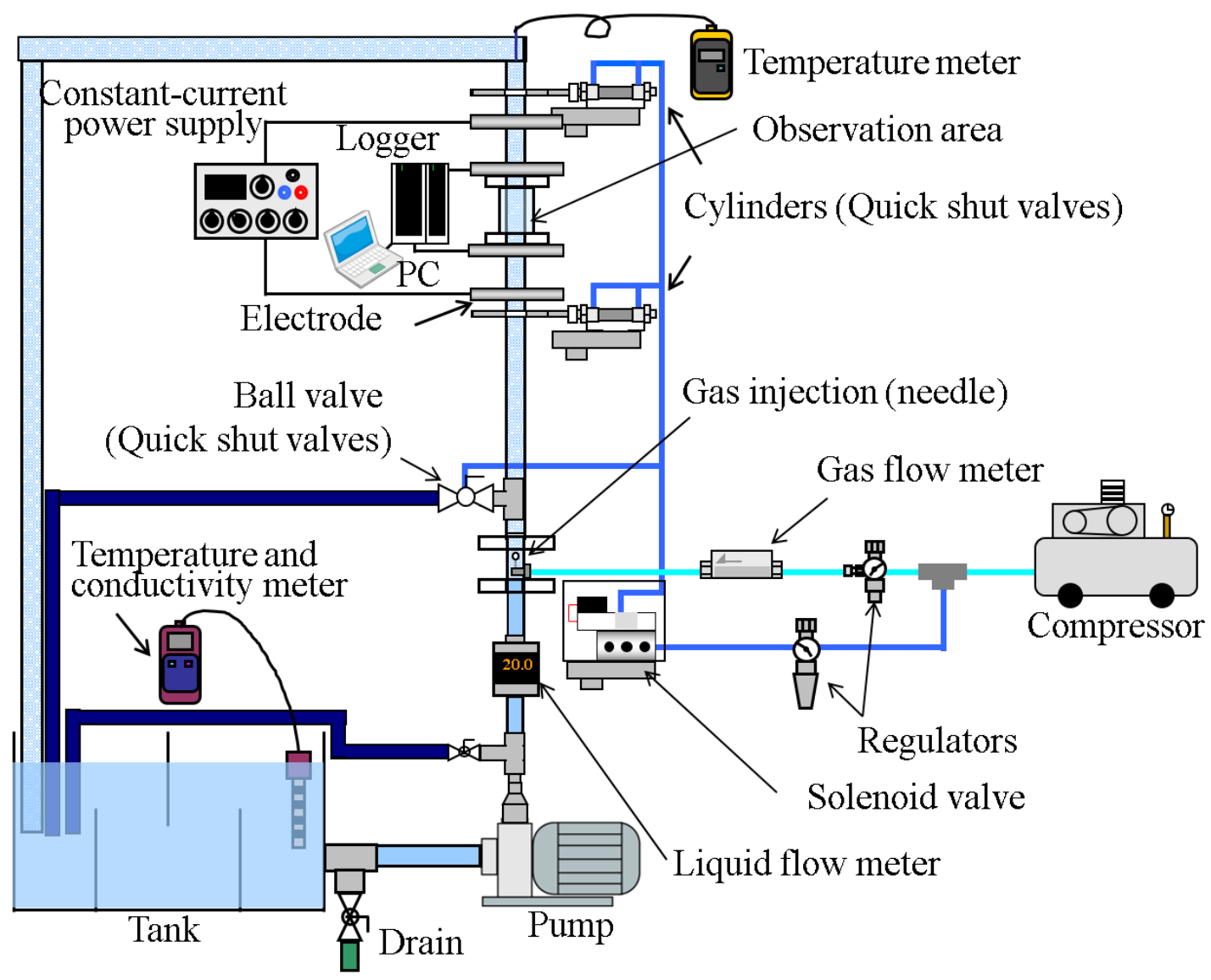

Figure 3. A schematic of the experimental setup to measure bubbly flow and bubbly-slug flow.

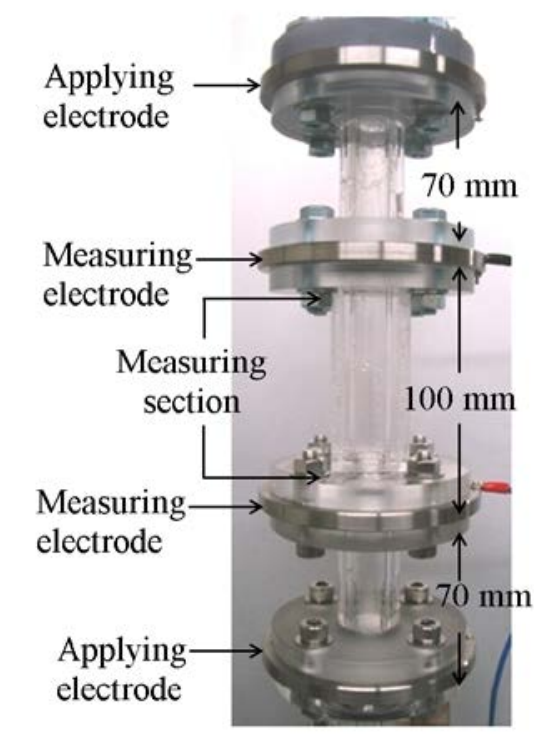

Figure 4. A snapshot of the electric void sensor. 

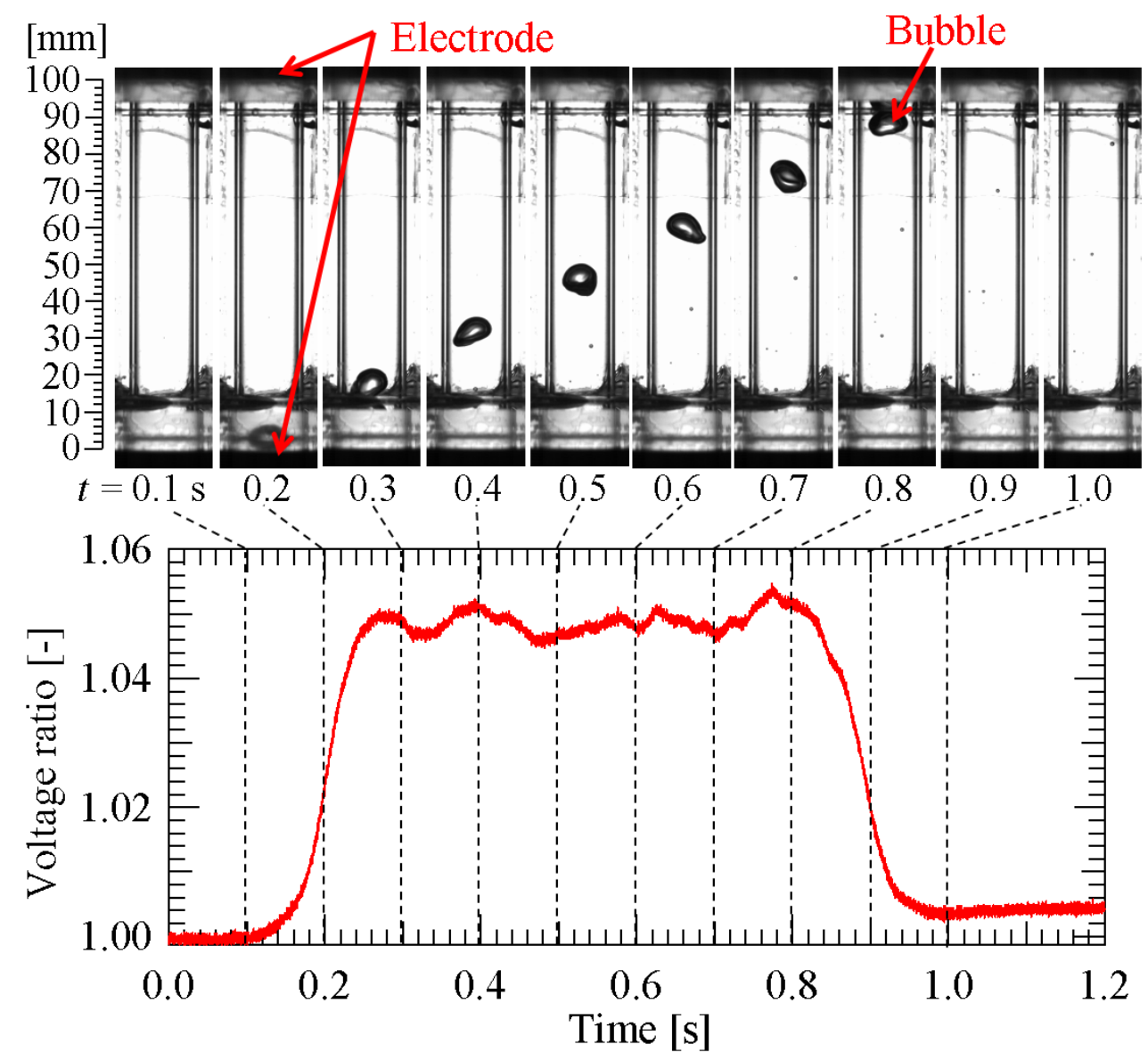

Figure 5. Time series of the voltage ratio for a rising single bubble without forced convection. Snapshots showed bubble behaviors for each time.

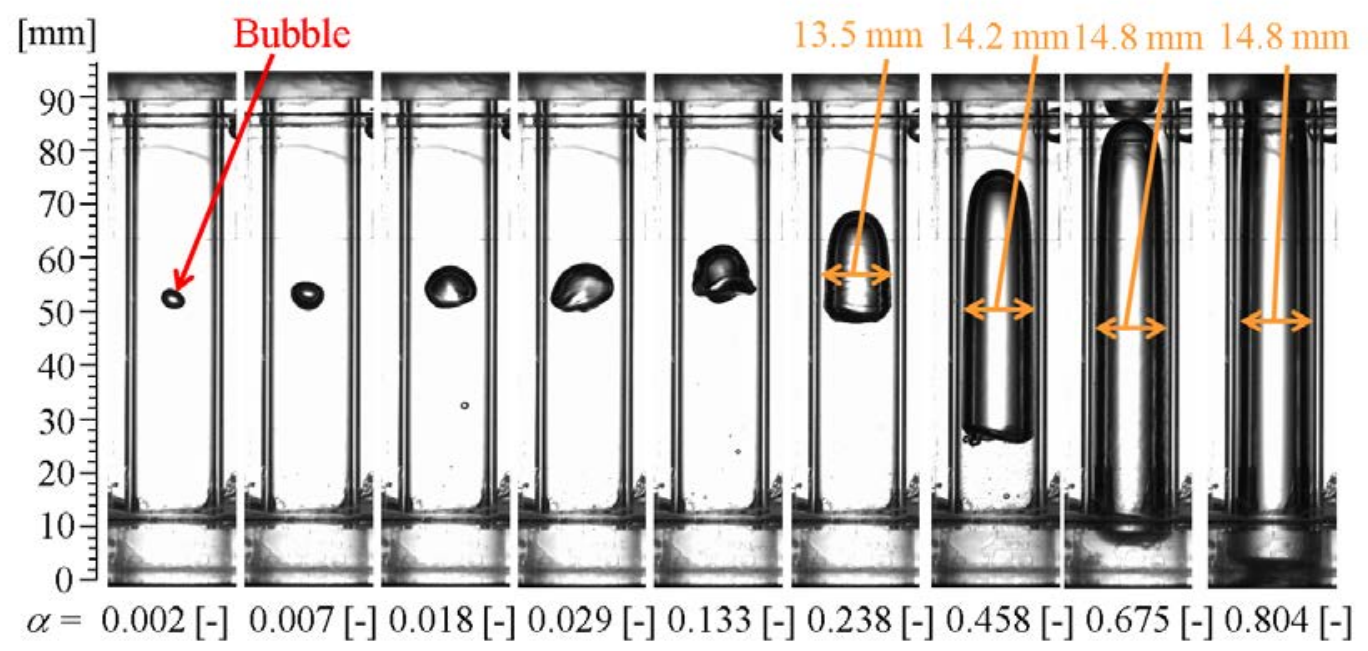

Figure 6. Snapshots of the rising single bubble behavior between the measuring electrodes for each void fraction. 


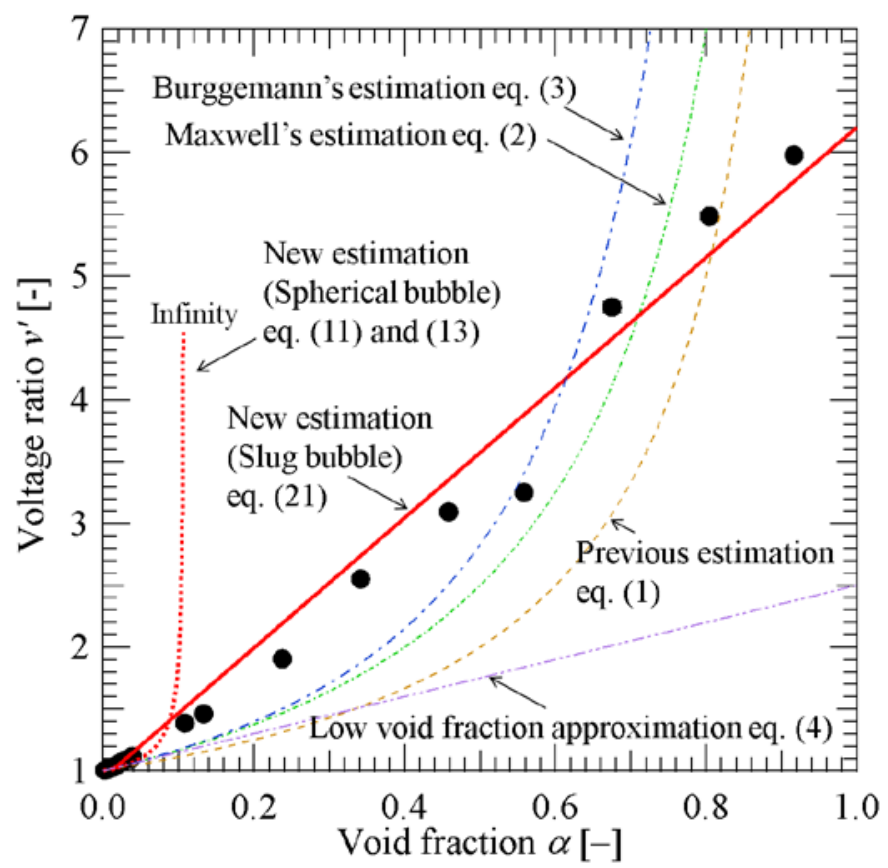

Figure 7. The correlation between the voltage ratio and the void fraction for a single bubble. Plots indicated experimental results. Lines were results of each estimation methods.

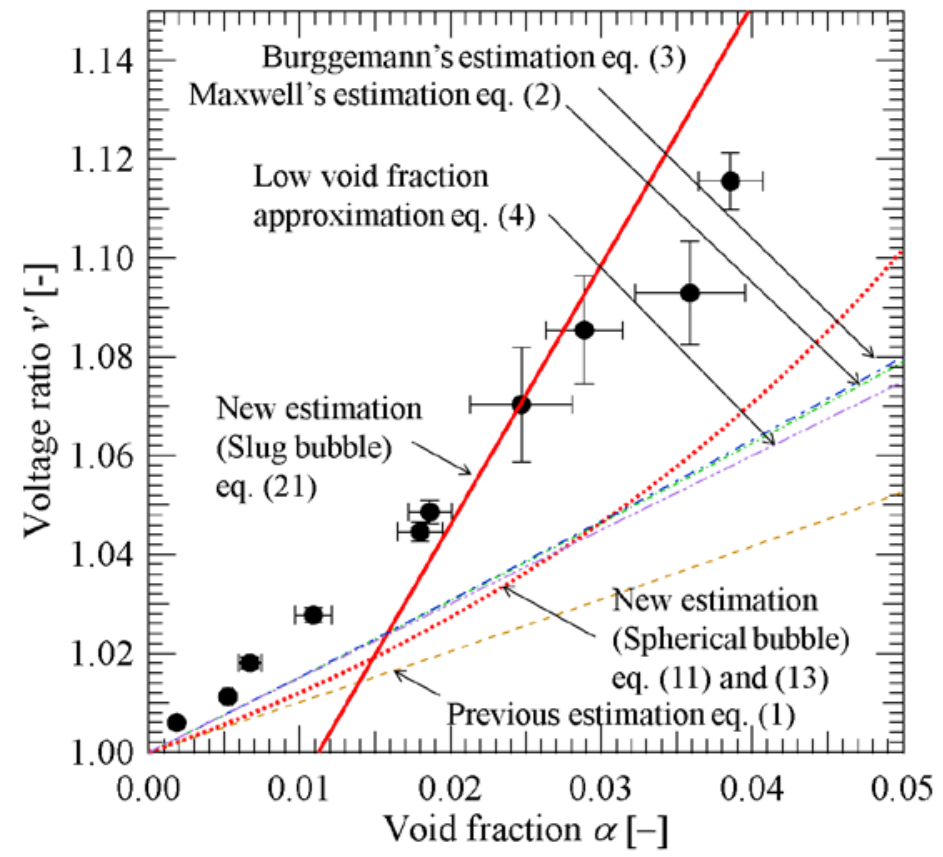

Figure 8. The correlation between the voltage ratio and the void fraction in low void fraction of a single bubble. Plots indicated experimental results. Lines were results of each estimation methods. 


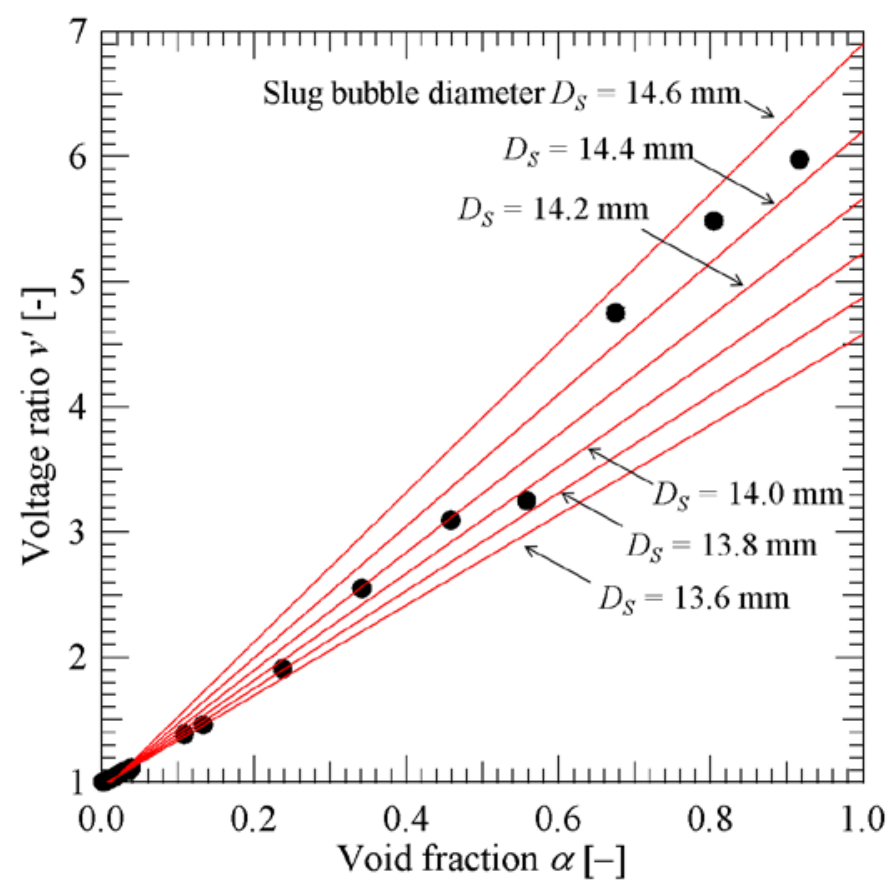

Figure 9. The correlation between the voltage ratio and the void fraction for each diameter of a slug bubble. Plots indicated experimental results. Lines were results of the new estimation method for a slug bubble.

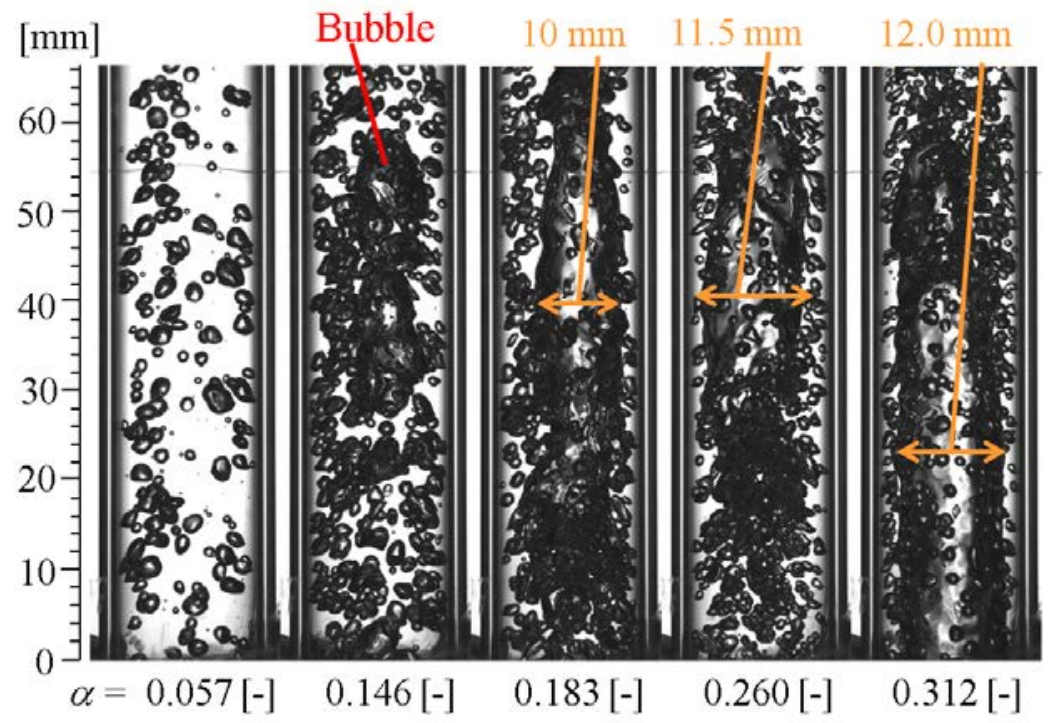

Figure 10. Snapshots of bubbly flow and bubbly-slug flow between the measuring electrodes for each void fraction. 


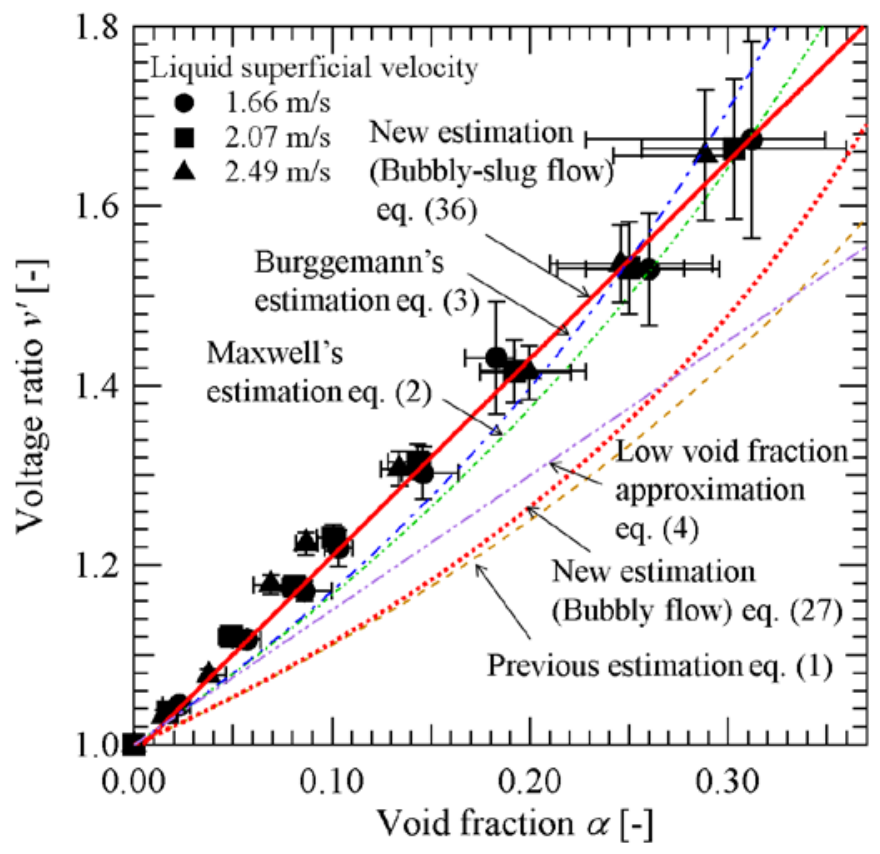

Figure 11. The correlation between the voltage ratio and the void fraction in bubbly flow and bubbly-slug flow. Plots indicated experimental results. Lines were results of each estimation methods.

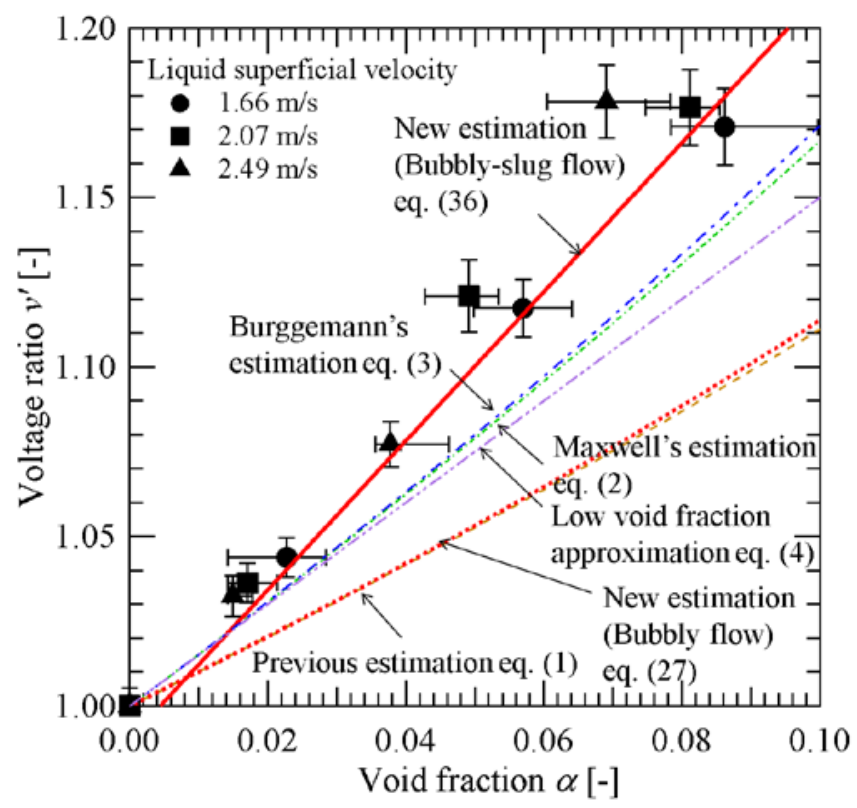

Figure 12. The correlation between the voltage ratio and the void fraction in low void fraction of bubbly flow and bubbly-slug flow. Plots indicated experimental results. Lines were results of each estimation methods. 


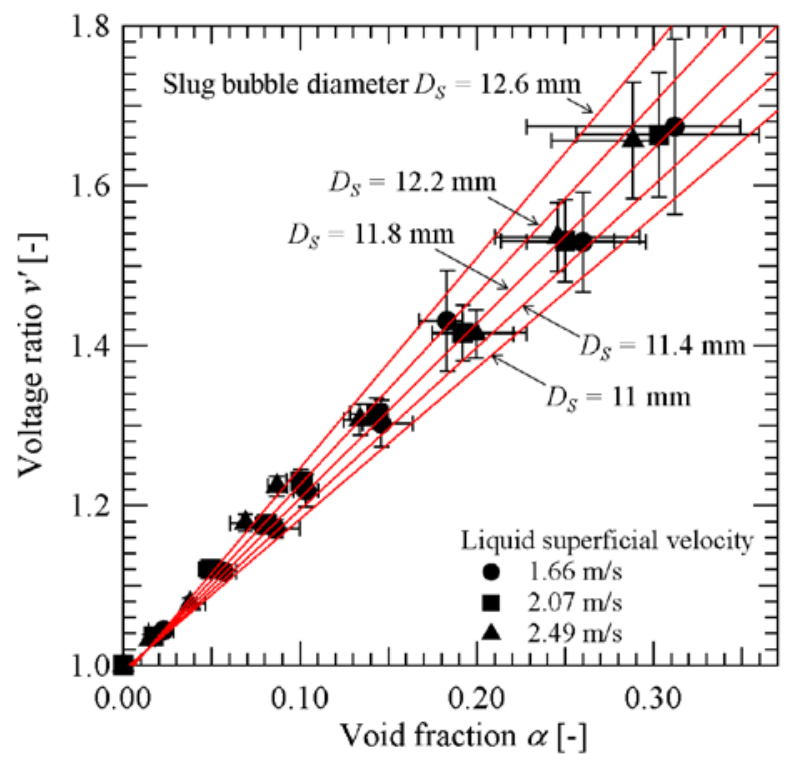

Figure 13. The correlation between the voltage ratio and the void fraction for each diameter of a slug bubble in bubbly-slug flow. Plots indicated experimental results. Lines were results of the new estimation method for bubbly-slug flow with the radius of spherical bubbles $r_{b}=0.5 \mathrm{~mm}$.

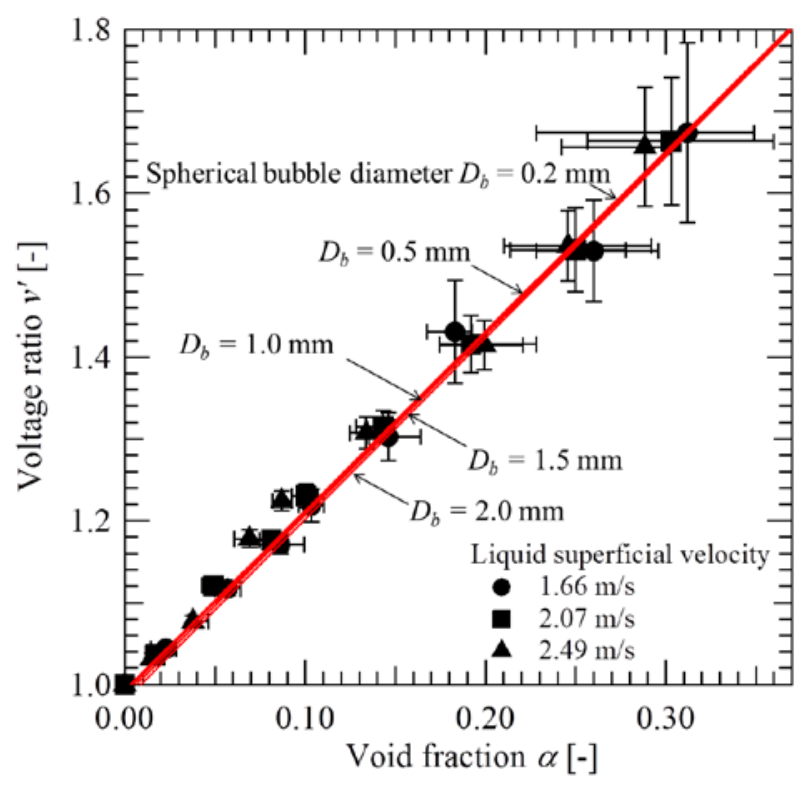

Figure 14. The correlation between the voltage ratio and the void fraction for each diameter of bubbles in bubbly-slug flow. Plots indicated experimental results. Lines were results of the new estimation method for bubbly-slug flow with the radius of a slug bubble $r_{s}=5.9 \mathrm{~mm}$. 


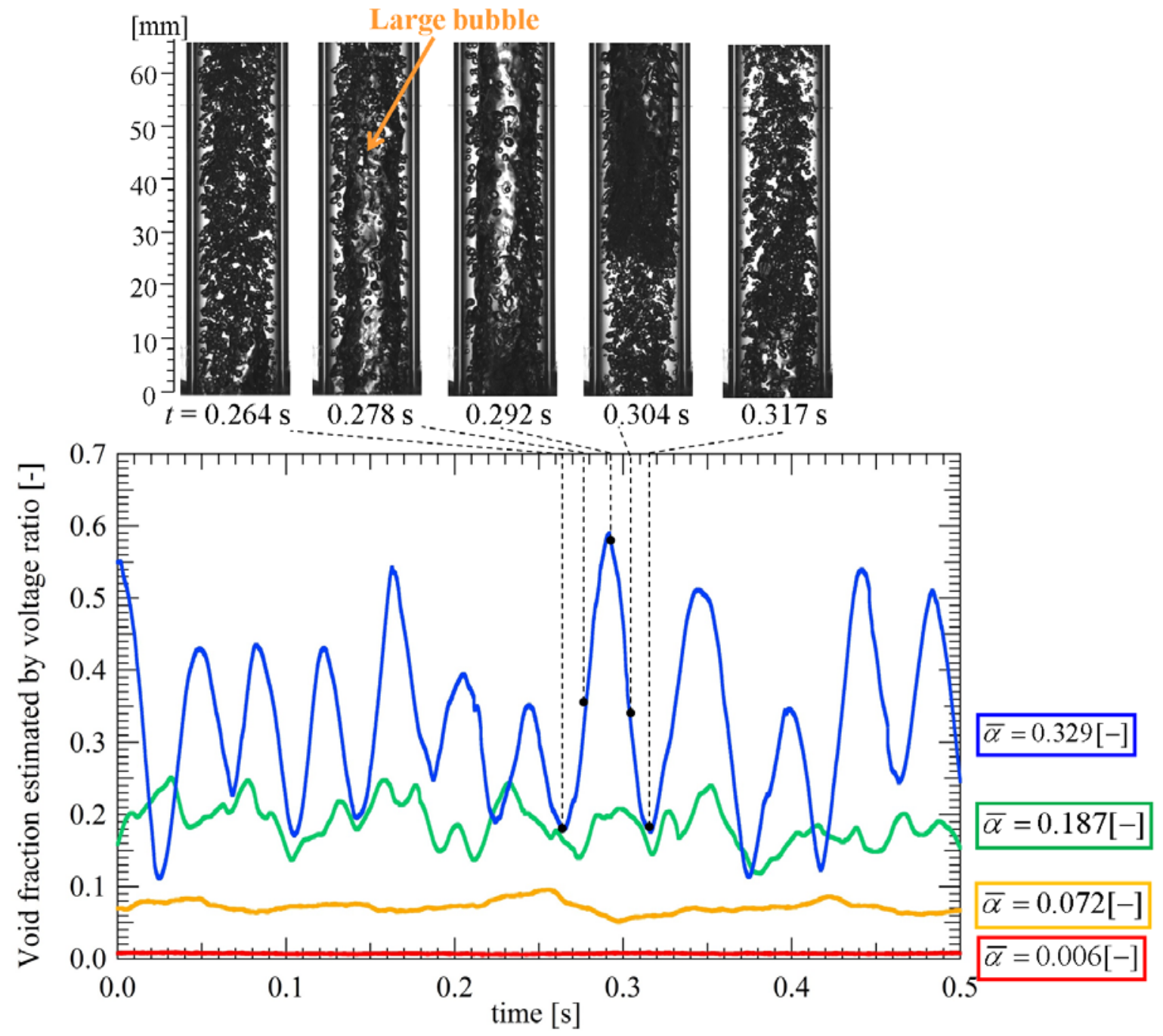

Figure 15. Temporal fluctuations of void fractions in bubbly flow and bubbly-slug flow with each time-average void fraction. Snapshots showed the bubble behavior for each time. 